\title{
Efektivitas Pelatihan Mindfulness untuk Menurunkan Ego Depletion pada Mahasiswa Baru
}

\author{
Vonny Syafira Hariyanto ${ }^{1}$ E Ira Paramastri $^{2}$ \\ Fakultas Psikologi Universitas Gadjah Mada Yogyakarta
}

\begin{abstract}
This study aimed to test the effectiveness of mindfulness-based interventions to decrease ego depletion in new students. Hypothesis in this research was mindfulnessbased intervention could decrease ego depletion of the new student. This study used a quasi-experimental method untreated-control-group design with pretest-postest using switching replication. This intervention consisted of one session plus an opening session, planning and closing. A total of 15 new students with moderate to high ego depletion were divided into control group (8 students) and experiment group (7 students). The instruments used in this study are EDS and KIMS. Quantitative analysis was performed by Mann-Whitney statistical test and qualitative analysis. The results showed that mindfulness-based intervention could significantly decrease ego depletion in new students $(\mathrm{U}=0.000, \mathrm{p}<0.001)$ and the therapeutic effect of the intervention could persist at least two weeks post-intervention.
\end{abstract}

Keywords: ego depletion; mindful breathing; mindfulness

\begin{abstract}
Abstrak. Penelitian ini bertujuan untuk menguji efektivitas intervensi berbasis mindfulness terhadap penurunan ego depletion pada mahasiswa baru. Hipotesis dalam penelitian ini adalah intervensi berbasis mindfulness yang dapat menurunkan ego depletion mahasiswa baru. Penelitian ini merupakan studi eksperimen kuasi dengan untreated-control-group design with pretest-postest using switching replication. Intervensi ini terdiri atas satu sesi ditambah dengan sesi pembuka, perencanaan dan penutup. Sebanyak 15 mahasiswa baru dengan ego depletion sedang hingga tinggi dibagi menjadi kelompok kontrol dan eksperimen. Instrumen yang digunakan pada penelitian ini adalah EDS dan KIMS. Analisis kuantitatif dilakukan dengan uji statistik Mann-Whitney disertai analisis kualitatif. Hasil penelitian menunjukkan bahwa intervensi berbasis mindfulness signifikan dalam menurunkan ego depletion pada mahasiswa baru $(U=0,000$; $p<0,001)$ serta efek terapeutik intervensi ini dapat bertahan setidaknya dua minggu pascaintervensi.
\end{abstract}

Kata kunci: ego depletion; menyadari nafas; mindfulness

Individu mengalami variasi kondisi psikologis yang berbeda-beda setiap harinya. Aktivitas kontrol diri individu untuk melakukan kegiatan sehari-hari

${ }^{1}$ Korespondensi dapat dilakukan melalui: vsyafira@gmail.com

${ }^{2}$ Atau melalui ira paramastri@ugm.ac.id memerlukan energi dalam jumlah yang ter batas untuk bekerja. Salah satu model kontemporer yang menjelaskan mengenai self control adalah strength model of self-control (Muraven \& Baumeister, 2000). Model ini menjelaskan bahwa setiap kali individu melakukan kontrol diri, maka 
sebagian energi psikis akan terkuras untuk sementara waktu. Terkurasnya energi psikis tersebut mengakibatkan besarnya kemungkinan kegagalan kontrol diri yang dilakukan pada pekerjaan individu berikutnya. Keadaan tersebut dinamakan sebagai ego depletion, yakni keadaan berkurangnya energi psikis karena melakukan kontrol diri (Baumeister, Vohs, \& Tice, 2007). Energi psikis diperlukan bagi individu untuk mengontrol pikiran, perasaan, dan perilaku. Baumister, et al. (2007) medeskripsikan ego depletion sebagai kondisi saat individu menjadi lebih pasif sehingga sulit membuat orientasi perilaku untuk mencapai tujuan yang diinginkan. Pada kondisi ini individu sulit berpikir secara efektif. Kondisi ego depletion juga ditunjukkan dengan perilaku individu yang "masa bodoh" terhadap serangkaian tugas yang seharusnya segera diselesaikan (Schmeichel, Vohs, Baumeister, 2003).

Dampak dari ego depletion pada kehidupan sehari-hari dapat muncul dalam berbagai domain perilaku. Misalnya, saat indivdu mengalami ego depletion akan mengakibatkan individu meminum alkohol lebih banyak (Muraven, Collins, Morsheimer, Shiffman, \& Paty, 2005; Muraven \& Shmueli, 2006). Dalam hubungan interpersonal, ego depletion mengakibatkan individu lebih sulit memaafkan (Finkel \& Campbell, 2001) dan keadaan ego depletion membuatnya lebih tertarik pada individu yang bukan pasangannya (Ritter, Karremans, \& Schie, 2010). Dalam konteks agresi, ego depletion mengakibatkan individu lebih rentan untuk melakukan agresi (DeWall, Baumeister, Stillman, \& Gailliot, 2007; Stucke \& Baumeister, 2006).
Manifestasi ego depletion yang ekstrim dalam persoalan personal juga muncul dalam dunia pendidikan. Salah satu permasalahan mahasiswa baru. Mahasiswa mengalami banyak perubahan di tahun pertamanya kuliah saat memasuki perguruan tinggi. Hal ini terkait dengan penyesuaian yang merupakan masalah berat yang harus dihadapi individu ketika memasuki dunia kuliah (Dyson \& Renk, 2006). Pada umumnya, individu memasuki dunia perkuliahan pada usia 18 tahun. Menurut Turner \& Helms (1995) usia 17-22 tahun merupakan tahapan pertama dari era dewasa muda yang ditandai dengan adanya transisi dari remaja (masa pra dewasa) ke kehidupan dewasa. Pada usia ini pula seseorang memasuki bangku perkuliahan sebagai jalur penting menuju kedewasaan (Papilia, Feldman, \& Olds, 2007). Kondisi ini membawa individu pada dua transisi yang harus dijalankan pada satu waktu, dari remaja ke dewasa dan dari senior di SMA menjadi mahasiswa baru di perguruan tinggi. Greenberg (1999) secara khusus merangkum masalah yang dihadapi mahasiswa baru (yang memasuki perkuliahan setelah lulus dari SMA), yaitu: perubahan gaya hidup (masa transisi dari SMA ke Universitas), nilai, jumlah mata kuliah yang diambil, masalah pertemanan, cinta, rasa malu, dan kecemburuan. Murphy dan Archer (dalam Duffy \& Atwater, 2005) menambahkan bahwa persaingan antar mahasiswa yang tinggi merupakan salah satu pemicu stres bagi mahasiswa. Berbagai penyesuaian yang harus dihadapi untuk mampu membuat individu bertahan dalam perkuliahan maupun lingkungan sosialnya. Selain itu, jauhnya para mahasiswa dari orang tua dan sanak saudara yang harus dihadapi 
mahasiswa, kemampuan dalam mengelola keuangan secara mandiri. (Utomo, 2008).

Survei yang dilakukan Nadjuddan (2003) di Universitas Hasanuddin dengan responden 150 mahasiswa menyebutkan bahwa sebanyak $63,21 \%$ mahasiswa baru mengalami masalah penyesuaian diri, $51,24 \%$ mengalami masalah pada teknik belajar, dan 58,73\% mahasiswa mengalami masalah pengembangan karier. Penelitian Abdulghani (2008) merangkum stres berdasarkan tingkatan mahasiswa yaitu pada mahasiswa tingkat pertama mencapai $74,2 \%$, mahasiswa tingkat kedua mencapai 69,8\%, mahasiswa tingkat ketiga mencapai $48,6 \%$ dan mahasiswa tingkat keempat mencapai 30,4\%. Penelitian tentang perbandingan stres juga dilakukan di Fakultas Kedokteran Universitas Lampung. Penelitian ini menunjukkan bahwa pada mahasiswa tingkat pertama tingkat stres sedang sampai berat mencapai $72,6 \%$, sedangkan pada mahasiswa tingkat akhir tingkat stres sedang sampai berat mencapai $55 \%$ (Augesti, 2015). Berdasarkan hasil kedua penelitian tersebut terlihat bahwa tingkat stres lebih banyak dialami oleh mahasiswa tingkat pertama dibandingkan mahasiswa tingkat akhir.

Dengan demikian dapat disimpulkan bahwa kondisi-kondisi perubahan pada mahasiswa tahun pertama mempunyai kecenderungan mengalami ego depletion. Hal ini didukung oleh data layanan bimbingan konseling mahasiswa di pusat kesehatan mahasiswa. Sejak bulan Maret 2016 hingga Maret 2017 diketahui ada $44 \%$ dari jumlah mahasiswa yang ditangani BKM ialah mahasiswa di tahun pertama. Dengan keluhan yang paling sering adalah kesulitan belajar dan kehilangan konsentrasi belajar.

Salah satu teknik resolusi self control yang efisien adalah latihan mindfulness. Terapi mindfullness melatih individu agar tidak melakukan penilaian yang otomatis terhadap peristiwa yang sedang dialami. Penilaian otomatis akan membuat individu tidak melakukan penilaian secara objektif, sehingga koping yang dilakukan seringkali tidak tepat dan berakibat koping menjadi tidak efektif (Bowen, Chawla, \& Marlatt. 2010). Di Indonesia, penggunaan mindfulness juga memiliki kemiripan dengan budaya Jawa "eling" yang dijelaskan oleh Koentjaraningrat (Yusainy, 2013) yang berarti selalu memiliki kesadaran terhadap kedudukan diri sendiri dalam kehidupan.

Metode mindfulness yang digunakan dalam penelitian ini merupakan adaptasi dari pelatihan mindfulness yang telah dilakukan Yusainy (2013). Mindfulness merupakan pendekatan yang efektif, tanpa biaya, dan tanpa efek samping (Gregoire, 2014). Temuan empiris mengenai latihan mindfulness telah banyak digunakan untuk mengurangi angka gangguan klinis seperti stres (Brown \& Ryan, 2003), regulasi emosi (Archer \& Coyne, 2005), gangguan kecemasan (Kabat-Zinn, 2003), depresi (Segal, Williams, Taesdale, 2012), tindakan kompulsif dan gangguan makan (Kalat, 2010), dan gangguan kulit (KabatZinn, 1998).

Penelitian mengenai pengaruh mindfulness dan ego depletion masih dapat dikatakan terbatas. Beberapa penelitian yang meneliti pengaruh mindfulness dan self control terhadap perilaku agresif dilakukan oleh Yusainy \& Lawrence (2014), dan Yusainy (2013). Penelitian korelasional oleh Yusainy \& Lawrence (2014) menemukan bahwa individu 
dengan kemampuan mindfulness dan kontrol diri yang tinggi memiliki kecenderungan agresi yang rendah.

Penelitian eksperimen oleh Yusainy (2013) yang dilakukan di Indonesia menemukan bahwa mindfulness dapat mengurangi agresi dalam kondisi ego depletion. Intervensi mindfulness dapat memfasilitasi individu untuk belajar menghadapi setiap pengalaman dengan lebih terbuka dan tanpa penilaian. Metode mindfulness menggunakan serangkaian latihan yang didesain untuk melatih pikiran agar dapat tetap fokus dan terbuka pada kondisi sehari-hari termasuk dalam kondisi penuh tekanan (Chielsa \& Malinowski, 2011).

Penelitian Brown, Weinstein, \& Creswell (2012) menunjukkan bahwa individu dengan skor mindfulness yang tinggi menunjukkan respon kortisol yang lebih kecil pada saat menghadapi situasi yang penuh tekanan, dan juga menunjukkan kondisi emosi negatif yang lebih rendah.

Berdasarkan uraian tersebut, diperoleh kesimpulan bahwa ego depletion pada mahasiswa baru dapat diturunkan dengan mengoptimalkan kembali selfcontrol yang telah terforsir akibat melakukan serangkaian aktivitas, secara otomatis sumber daya pribadi akan meningkat sehingga akan lebih efektif dalam melakukan tugas-tugas keseharian selanjutnya. Salah satu cara agar dapat meningkatkan self-control secara efektif adalah menghindari penilaian otomatis dengan berlatih mindfulness.

Penelitian ini bermaksud untuk menguji efektivitas mindfulness terhadap penurunan ego depletion pada mahasiswa baru. Penelitian dilakukan untuk melihat pengaruh terapi terhadap ego depletion mahasiswa. Penelitian ini melibatkan dua kelompok yaitu kelompok eksperimen dan kelompok kontrol.

\section{Metode}

Variabel independen penelitian ini adalah Intervensi Berbasis Mindfulness. Modul intervensi yang digunakan dalam penelitian ini telah dimodifikasi oleh Yusainy (2013) berdasarkan modul yang disusun oleh Kabat Zinn (2005). Variabel dependen dalam penelitian ini adalah ego depletion. Subjek penelitian ini adalah Mahasiswa baru S1 Universitas Gadjah Mada angkatan 2017-2018, Belum pernah memiliki pengalaman formal terkait latihan mindfulness, Berusia antara 18 hingga 24 tahun, mahasiswa dengan kriteria tersebut, mengalami ego depletion sedang hingga tinggi (yang akan diukur terlebih dahulu dengan skala ego depletion dengan rentang skor 70-110 untuk ego depletion sedang, dan >110 ego depletion tinggi). Subjek diambil dengan menggunakan teknik purposive sampling, jumlah subjek dalam penelitian ini adalah 15 mahasiswa baru yang terbagi menjadi dua kelompok yaitu 7 orang di kelompok eksperimen dan 8 orang di kelompok kontrol.

Alat ukur yang digunakan untuk mengukur kondisi ego depletion adalah skala ego depletion EDS yang dibuat oleh Undarwati (2012). Selain digunakan sebagai pretes dan postes, peneliti juga menggunakan skala EDS sebagai sarana untuk mendapatkan subjek dengan kriteria mengalami ego depletion sedangtinggi. Skala ego depletion dalam penelitian Undarwati (2012) menghasilkan perhitungan berdasarkan item-total correlation, nilai $\mathrm{r}$ atau indeks daya beda aitem antara 0.333 sampai 0.765 dengan nilai alpha Cronbach 0.931 . Dengan demikian dapat dikatakan bahwa 
skala ego depletion merupakan alat ukur yang cukup reliabel.

Untuk mengukur manipulasi, digunakan skala KIMS yang disusun oleh Baer, Smith, dan Allen (2004) dan telah divalidasi oleh Yusainy (2013). Hasil pengukuran Aiken's $V$ terhadap lima ahli menunjukkan hasil rerata Aiken's $V$ sebesar 0.898. Berdasarkan hasil analisis terdapat 24 aitem dengan nilai $\alpha=0,817$. KIMS diberikan setelah partisipan melakukan meditasi mindfulness untuk memastikan apakah instruksi mindfulness dapat mem-bangkitkan kondisi mindfulness.

Penelitian ini merupakan eksperimen semu atau eksperimen kuasi (quasi experiment) yaitu eksperimen yang dilakukan tanpa randomisasi tetapi memiliki tujuan dan atribut struktural yang sama dengan randomized experiment (Shadish, Cook, \& Campbell, 2002). Penelitian dilakukan untuk melihat pengaruh terapi terhadap ego depletion pada mahasiswa. Disain yang digunakan pada penelitian ini adalah untreated control group with pretest and posttest using switching replication dengan purposive sampling sesuai dengan kriteria yang telah ditentukan. Kelompok eksperimen mendapatkan intervensi berbasis mindfulness sebanyak satu sesi terapi dan dua sesi tambahan yaitu pembuka dan follow-up. Kelompok kontrol mendapatkan pretest kemudian postest tanpa mendapatkan terapi.

Uji hipotesis penelitian ini menggunakan teknik statistika non parametrik. Hal ini dikarenakan jumlah partisipan pada penelitian $<20$ orang. Teknik non parametrik yang digunakan yaitu uji Mann Whitney. Uji ini bertujuan untuk melihat perbedaan skor antara dua kelompok yaitu kelompok eksperimen dan kelompok kontrol. Analisis data dilengkapi juga dengan analisis deskriptif berupa hasil observasi dan wawancara partisipan penelitian. Selain observasi dan wawancara, data juga dilengkapi dengan hasil buku kerja partisipan dan buku latihan di rumah. Hal tersebut dilakukan untuk mengetahui perkembangan partisipan selama mengikuti program ini.

\section{Hasil}

Pelaksanaan penelitian intervensi berbasis mindfulness dilakukan di Fakultas Psikologi Universitas Gadjah Mada Yogyakarta. Penelitian ini melibatkan 15 partisipan yang terbagi menjadi dua kelompok yaitu tujuh orang pada kelompok eksperimen dan delapan orang pada kelompok kontrol.

Deskripsi data skor ego depletion kelompok eksperimen dan kontrol, dapat dilihat pada Tabel 1. Berdasarkan Tabel 1 dapat dijelaskan bahwa pada kelompok eksperimen, perubahan selisih skor terbesar dari postest dan pretest terjadi pada subjek AZ, yakni terjadi penurunan skor sebesar 43 poin. Perubahan selisih skor postest dan pretest terkecil, terjadi pada subjek AS yaitu dengan selisih skor 26 poin.

Gambaran perubahan skor ego depletion yang terjadi pada kelompok eksperimen dan kontrol saat sebelum dan setelah diberikan intervensi berbasis mindfulness dapat dilihat pada gambar 1 dan gambar 2.

Berdasarkan uji statistika, bahwa hipotesis diterima artinya terjadi penurunan ego depletion pada kelompok eksperimen jika dibandingkan dengan kelompok kontrol $U=0,000 \quad(p=0,000$; $p<0,05)$. Untuk mengetahui efek dari intervensi apakah masih dapat bertahan atau tidak setelah intervensi, Peneliti melakukan follow-up setelah dua minggu 
Tabel 1.

Data Deskriptif Skor Ego Depletion Pretest Dan Posttest pada Kedua Kelompok

$\begin{array}{cccccc}\text { Kelompok Nama } & \text { Pretes } & \begin{array}{l}\text { Kategori } \\ \text { Kategori }\end{array} & \text { Postes } & \text { Kategori } & \begin{array}{c}\text { Follow-up } \\ \text { up }\end{array}\end{array}$ Kategori G1

\begin{tabular}{ccccccccc} 
Eksperimen & AN & 100 & Sedang & 67 & Rendah & 65 & Rendah & -33 \\
& & & & & & & & \\
& AF & 103 & Sedang & 66 & Rendah & 65 & Rendah & -37 \\
& AS & 101 & Sedang & 67 & Rendah & 67 & Rendah & -26 \\
& AY & 112 & Tinggi & 76 & Sedang & 69 & Rendah & -36 \\
& AZ & 111 & Tinggi & 68 & Rendah & 66 & Rendah & -43 \\
& RP & 107 & Sedang & 67 & Rendah & 67 & Rendah & -40 \\
& NS & 103 & Sedang & 64 & Rendah & 64 & Rendah & -39 \\
& Total & 737 & & 475 & & 463 & & -262 \\
& Rerata & 105,285 & & 67,857 & & 66,142 & & $-37,42$ \\
\hline \multirow{5}{*}{ Kontrol } & CI & 110 & Sedang & 107 & Sedang & 69 & Rendah & -3 \\
& AS & 106 & Sedang & 104 & Sedang & 69 & Rendah & -2 \\
& AP & 112 & Tinggi & 112 & Tinggi & 71 & Sedang & 0 \\
& AR & 113 & Tinggi & 114 & Tinggi & 67 & Rendah & 1 \\
& RS & 109 & Sedang & 111 & Tinggi & 67 & Rendah & 2 \\
& DH & 100 & Sedang & 101 & Sedang & 73 & Sedang & 1 \\
& EF & 104 & Sedang & 103 & Sedang & 69 & Rendah & -1 \\
& GS & 104 & Sedang & 102 & Sedang & 71 & Sedang & -2 \\
& Total & 858 & & 854 & & 556 & & -4 \\
\hline & Rerata & 107,25 & & 106,75 & & 69,5 & & $-0,5$ \\
\hline
\end{tabular}

Keterangan. G1 = Skor postes-skor pretes

intervensi. Untuk melakukan analisis terhadap efek intervensi, peneliti melakukan uji wilcoxson yaitu membandingkan antara hasil follow-up dan pretes. Efek intervensi berbasis mindfulness terhadap penurunan ego depletion masih dapat bertahan paling tidak selama dua minggu setelah intervensi dengan $Z=-2.375 \quad(p=0,018$; $p<0,05)$.

Pada kelompok kontrol, setelah diberi postest, peneliti memberikan intervensi yang sama dengan yang diterima oleh kelompok eksperimen sebagai salah satu bentuk etika penelitian. Pengukuran dilakukan setelah intervensi selesai dilaksanakan. Untuk mengetahui hasil intervensi tersebut, peneliti menganalisis skor follow-up kelompok kontrol dengan skor postest. Analisis dilakukan dengan menggunakan uji wilcoxson, diperoleh hasil $\mathrm{Z}=-2,542$ $(p=0,012 ; \quad p<0,05)$. Berdasarkan hasil tersebut disimpulkan terdapat perbedaan signifikan antara skor ego depletion sebelum dan setelah intervensi berbasis mindfulness.

Sumbangan efektif (effect size) intervensi berbasis mindfulness terhadap penurunan ego depletion dalam penelitian ini diperoleh nilai $\mathrm{r}=0,84$ (efek besar). Hal tersebut menunjukkan bahwa sumbangan efektif intervensi berbasis mindfulness terhadap penurunan ego depletion sebesar 84\%. Berdasarkan pemaparan di atas, dapat disimpulkan bahwa kelompok yang mendapatkan intervensi berbasis mindfulness, dapat 
menurunkan ego depletion, sementara kelompok kontrol yang tidak mendapatkan intervensi berupa intervensi berbasis mindfulness kondisi ego

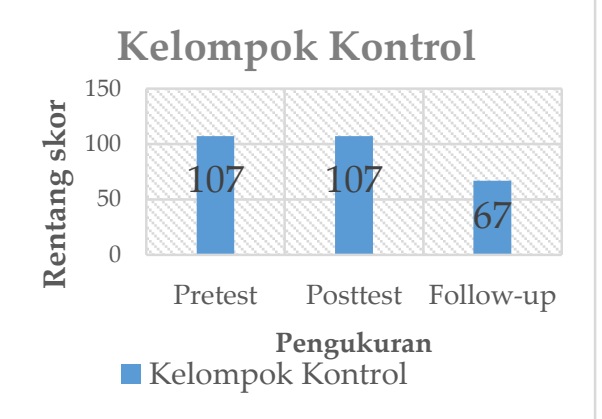

Gambar 1. Rerata skor ego depletion KE

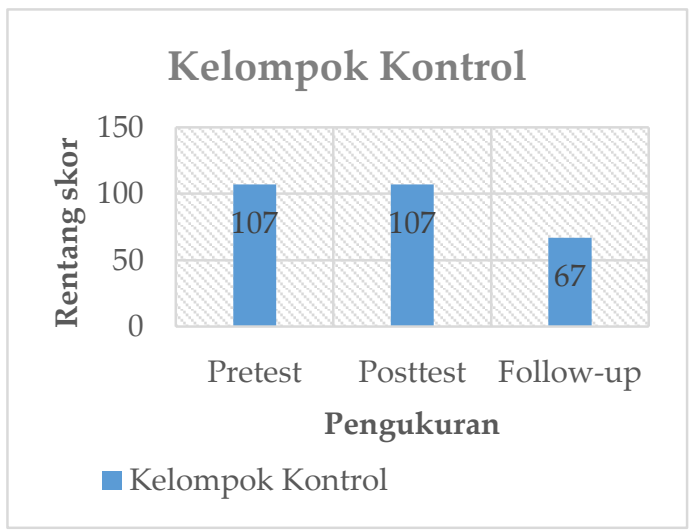

Gambar 2. Rerata skor ego depletion KK

depletion cenderung stabil. Efek dari intervensi berbasis mindfulness dapat bertahan paling tidak selama dua minggu saat postes dilaksanakan. Hal tersebut menunjukkan bahwa intervensi berbasis mindfulness terbukti dapat menurunkan ego depletion pada mahasiswa dan efek teraputik dari intervensi ini dapat bertahan selama dua minggu, serta sumbangan efektif dari intervensi ini dalam menurunkan ego depletion sebesar $84 \%$.

Pengukuran manipulation check menggunakan KIMS dilakukan dengan menganalisis perbedaan skor dua kelompok pada saat sebelum dan sesudah intervensi berbasis mindfulness. Hasil analisis dengan menggunakan uji MannWhitney menunjukkan $\mathrm{U}=0000 ; \mathrm{p}<0,01$. Hal tersebut menunjukkan bahwa terdapat perbedaan yang signifikan sebelum dan sesudah intervensi berbasis mindfulness antara kelompok kontrol dan kelompok eksperimen.

Hasil observasi dianalisis dengan menggunakan korelasi interklas untuk mengetahui kesepakatan antar observer. Berdasarkan hasil analisis, diketahui bahwa rerata kesepakatan antar observer sebesar 0,938 dengan konsistensi tiap observer sebesar 0,833. Hasil tersebut menunjukkan bahwa kesepakatan antar observer mendekati sempurna dengan hasil ketercapaian tujuan intervensi sebesar 97\%. Berdasarkan data tersebut disimpulkan bahwa tujuan intervensi telah tercapai dengan baik.

\section{Diskusi}

Intervensi berbasis mindfulness terbukti secara signifikan dapat menurunkan ego depletion pada mahasiswa baru. Hasil analisis skor ego depletion juga diperkuat hasil analisis cek manipulasi yaitu skala KIMS. Hasil analisis dengan uji MannWhitney yaitu $U=0,000 ; p<0,01$. Hal tersebut menunjukkan bahwa terdapat perbedaan yang signifikan antara skor mindfulness pada kedua kelompok eksperimen dan kelompok kontrol. Dengan demikian disimpulkan bahwa skala KIMS sebagai cek manipulasi memiliki nilai validitas konstruk yang baik. Oleh karena itu, skala KIMS dapat mengukur proses intervensi sesuai dengan konstruk teoritis dari intervensi berbasis mindfulness ini, sehingga dapat menunjukkan perbedaan antara sebelum dan sesudah intervensi.

Tidak hanya signifikan untuk menurunkan ego depletion, efek teraputik 
intervensi berbasis mindfulness ini juga dapat bertahan dua minggu setelah pemberian intervensi berakhir. Hal ini dapat dilihat dari tidak adanya perbedaan yang signifikan antara skor ego depletion pada saat follow-up dan pada saat pretes. Hal tersebut sejalan dengan penelitian Cahn \& Polich (2006) yang menemukan bahwa intervensi berbasis mindfulness pada pasien kanker dapat bertahan hingga enam bulan. Penelitian Chiesa \& Serretti (2009) menunjukkan bahwa intervensi mindfulness pada pasien skizofrenia dapat bertahan hingga dua tahun.

Keberhasilan intervensi ini salah satunya disumbangkan dari modul yang telah disusun sebelumnya, yang terbukti signifikan untuk meningkatkan skor keterampilan mindfulness. Pelaksanaan intervensi berjalan dengan lancar. Subjek penelitian mengikuti rangkaian kegiatan dalam tempat yang memadai. Berdasarkan hasil pengamatan tiga orang observer diperoleh kesepakatan bahwa ketercapaian kegiatan ini tergolong excellent. Ketercapaian indikator keberhasilan tiap sesi intervensi sebesar 97\%. Hal tersebut menunjukkan bahwa intervensi ini telah dilakukan sesuai dengan indikator yang telah ditetapkan sebelumnya.

Pada mindfulness, teknik menyadari nafas menjadi hal yang tidak dapat dipisahkan. Kabat Zinn (2000) menyebutkan bahwa latihan nafas secara mindful dapat membantu individu untuk menenangkan tubuh dan pikiran sehingga dapat melihat sesuatu lebih jelas dan jernih, dan memungkinkan untuk melihat dari sudut pandang yang lebih luas dan dapat melakukan pemecahan masalah secara lebih kreatif. Hal tersebut dapat membuat seseorang menjalani hidup dengan lebih rileks dan dapat menurunkan kelelahan psikis.

Pada latihan mindfulness nafas berkesadaran ini subjek menyatakan bahwa seperti diingatkan kembali bahwa dirinya telah berusaha dengan semaksimal mungkin, ketika mengalami masalah atau kegagalan, hal tersebut adalah hal yang sangat lumrah dan manusiawi. Melakukan latihan nafas berkesadaran sangat bermanfaat untuk meningkatkan kesejahteraan interpersonal dengan memahami bahwa penderitaan atau pengalaman tidak menyenangkan yang dialami dalam hidup merupakan sebagaian dari kondisi yang sangat manusiawi dan wajar untuk terjadi. Oleh karena itu, latihan tersebut dapat memberikan kemudahan terhadap individu ketika menghadapi situasi yang buruk. Latihan ini dapat membuat individu mampu mengolah emosi agar terarah saat menghadapi situasi yang tidak menyenangkan, sehingga dirinya dapat menjadi sahabat terbaik bagi dirinya sendiri.

Hal tersebut ditemukan dalam penelitian ini. Subjek mengatakan bahwa ketika mempraktikkan mindfulness nafas berkesadaran, rasanya seperti menyadari bahwa tubuhnya ada dan telah begitu hebatnya dapat bertahan dari segala tantangan yang selama ini dialami. Subjek dapat merasakan tubuhnya menerima sensasi apa saat itu. Subjek menjadi lebih sadar dan tidak mudah memberikan penilaian terhadap tubuhnya. Subjek mengatakan lebih dapat "mengerti" kondisi tubuhnya saat ini sehingga merasa lebih mencintai diri sendiri dan hal tersebut mampu menurunkan ketegangan dalam diri.

Subjek dalam penelitian ini mayoritas adalah subjek yang memiliki ketakutan yang besar untuk berjuang di kampus UGM, untuk dapat berjuang 
hingga lulus nanti. Seperti subjek AY yang merasa mengalami masalah karena tuntutan orang tua begitu tinggi sehingga ia takut gagal dan mengecewakan kedua orang tua. Subjek tersebut juga sering mengalami kekecewaan apabila dirinya belum berperilaku sesuai dengan harapan atau standar yang telah dibuat orang tua dan lingkungan kampusnya. Subjek juga sulit untuk menerima keadaan yang sedikit kompleks, misalnya ketika banyak tugas kampus dan bingung untuk mengatur waktu, hal tersebut membuatnya kaget dan panik karena berbeda dengan kondisi semasa SMA.

Penelitian ini membuktikan bahwa intervensi berbasis mindfulness efektif untuk menurunkan ego depletion pada mahasiswa baru. Hal ini sesuai dengan penelitian-penelitian sebelumnya yang mengatakan bahwa seseorang yang memperoleh skor tinggi pada mindfulness menunjukkan ego depletion yang lebih rendah dan dapat melakukan penilaian emosi yang lebih baik (Yusainy, 2013). Penelitian Brown et al. (2012) menunjukkan bahwa individu dengan skor mindfulness yang tinggi menunjukkan respon kortisol yang lebih kecil pada saat menghadapi situasi yang penuh tekanan, dan juga menunjukkan kondisi emosi negatif yang lebih rendah.

Adapun sistem kerja latihan mindfulness ialah, latihan mindfulness dapat menurunkan gelombang otak seseorang menjadi gelombang Alpha. Individu yang dapat mencapai gelombang Alpha, dapat menjadi rileks. Pada kesadaran di gelombang Alpha, seseorang menyadari keberadaannya dan mampu mengendalikan dirinya. Individu juga akan menjadi lebih tenang dan jernih dalam melihat pengalaman hidupnya, lebih mampu berpikir kreatif dalam memecahkan masalah karena tidak melakukan penilaian secara otomatis (Duncan, Coastworth, \& Greenberg, 2009).

Latihan pernafasan yang dilakukan dalam mindfulness dapat mengubah frekuensi gelombang otak menjadi lebih rendah, seperti gelombang Alpha dan Theta. Pola pernafasan yang dapat menurunkan gelombang otak adalah dengan melakukan pernafasan panjang, hingga lima kali permenit. (Cardaciotto, Herbert, Forman, Moitra, \& Farrow, 2008). Gelombang otak Alpha dapat memperlancar aliran darah yang menuju otak bagian frontal bawah, temporal superior dan korteks oksipital (Cahn \& Polich, 2006).

Bagian tersebut merupakan bagian yang terhubung dengan thalamus. Thalamus berfungsi menyampaikan sinyal sensoris dari bagian sistem syaraf ke cerebral korteks. Kondisi tersebut berdampak pada terciptanya proses berpikir yang terorganisir, tepat sasaran, menciptakan kesadaran yang stabil sehingga individu memiliki oritentasi yang benar terhadap lingkungan (Markam \& Markam, 2003). Selain itu, dampak lainnya adalah siklus tidur menjadi lebih teratur, meningkatkan kewaspadaan, serta meluaskan kesadaran mengenai realitas yang terjadi.

Ketika gelombang otak berada pada gelombang Alpha, kecemasan akan menurun serta munculnya perasaan yang tenang dan positif (Brown \& Ryan, 2003). Pada saat berada pada gelombang Alpha, individu akan menjadi lebih sensitif terhadap stimulus dan tubuh menjadi lebih rileks. Selain itu, kondisi Alpha akan memengaruhi sekresi hormon norepineprin, serotonin dan beta endoprhine dan penurunan tekanan darah. Oleh karena itu, kelelahan dapat menurun dan afek menjadi lebih positif, 
dan respon imun menjadi meningkat (Cozzolino, 2006). Selain manfaat tersebut di atas, penelitian lain menemukan bahwa Mindfulness terbukti secara general mampu meningkatkan atensi eksekutif (executive attention).

\section{Kesimpulan}

Intervensi berbasis mindfulness dapat menurunkan ego depletion pada mahasiswa baru. Efek dari intervensi yang diberikan terbukti dapat bertahan selama dua minggu setelah intervensi selesai diberikan. Hasil tersebut diperkuat dari hasil analisis cek manipulasi yang menunjukkan bahwa ada perubahan sebelum dan sesudah diberikan intervensi. Subjek merasakan adanya manfaat positif dan perubahan yang mereka alami setelah mengikuti intervensi, terutama pada saat latihan mindfulness nafas berkesadaran.

\section{Saran}

Segala pengukuran dan asesmen yang dilakukan pada penelitian ini didasarkan pada paper and pencil test, pada praktik kenyataan di lapangan, tidak dilakukan observasi ketika partisipan latihan di rumah. Terdapat ancaman dari kondisi ini bahwa partisipan menunjukkan kondisi yang optimum dalam tes tertulis, tetapi pada konteks nyata belum dapat dibuktikan. Oleh karena itu saran pada penelitian selanjutnya, seyogyanya dilakukan pengukuran dengan melakukan observasi langsung pada kegiatan sehari-hari yang dilakukan subjek oleh significant others di rumah subjek (others monitorin

\section{Daftar Pustaka}

Abdul Ghani, M. A., Matsuda, M., Jani, R., Jenkinson, C. P., Coletta, D. K., Kaku, K., DeFronzo, R. A. (2008).
The relationship between fasting hyperglycemia and insulin secretion in subjects with normal or impaired glucose tolerance. American Journal of Psysiology, 295(2), 401-406. doi: 10.1152/ajpendo.00674.2007

Archer, J., \& Coyne, S. M. (2005). An integrated review of indirect, relational, and social aggression. Personality and Social Psychology Review, 9(3), 212-230.

Augesti, G. (2015). Differences in stress level between first year and last year medical students in medical faculty of Lampung University. Medical Journal of Lampung University, 4(4), 50-56.

Baumeister, R. F., Vohs, K. D., \& Tice, D. M. (2007). The strength model of selfcontrol. Current Directions in Psychological Science, 16(6), 351-355.

Baer, R. A., Smith. G. T., Allen, K. B. (2004). Assessment of mind-fulness by selfreport: the Kentucky inventory of mindfulness skills. Assessment, 11(3), 191-206. doi: $\underline{10.1177 /}$ $\underline{1073191104268029}$

Brown, K. W., \& Ryan, R. M. (2003). The benefits of being present: Mindfulness and its role in psychological well-being. Journal of Personality and Social Psychology, 84(4), 822-848.

Brown, L. K., Weinstein, N., \& Creswell, J. D. (2012). Trait mindfulness modulates neuroendocrine and affective responses to social evaluative threat. Psycho neuroensdocrinology, 37, 2037-204. doi: 10.1016/j.psyneuen.2012.04. 003 Bowen, S., Chawla, N., \& Marlatt, G. A. (2010). Mindfulness-Based Relapse Prevention for addictive behaviors: A clinician's guide. New York: Guilford 
Press.

Cahn, B. R., \& Polich, J. (2006). Meditation states and traits: EEG, ERP, and Neuroimaging Studies. Psychological Bulletin, 132, 180-211. doi: $10.1037 / 0033-2909.132 .2 .180$

Cardaciotto, L., Herbert, J. D., Forman, E. M., Moitra, E., \& Farrow, V. (2008). The assessment of present moment awareness and acceptance: The Philadelphia mindfulness scale. Assesment, 18(3), 204-223. doi: $\underline{10.1177 / 1073191107311467}$

Chiesa, A., \& Serretti, A. (2009). Mindfulness-based stress reduction for stress management in healthy people: A review and meta-analysis. Journal of Alternative and Complementary Medicine, 15, 593-600. doi: 10. 1089/acm.2008.0495

Chielsa, A., \& Malinowski, P. (2011). Mindfulness-based approaches: Are they all the same?. Journal of Clinical Psychology, 67, 404-424. doi: 10.1007/s005200000206

Cozzolino, W. (2006). The nuts and bolts of meditation. California: Raissa Publisher.

DeWall, C. N., Baumeister, R. F., Stillman, T., \& Gailliot, M. T. (2007). Violence restrained: Effects of self-regulation and its depletion on aggression. Journal of Experimental Social Psychology, 43(1), 62-76.

Duffy, K. G., \& Atwater, E (2005). The psychology of health, ilness and medical care. Pacific Grove, California: Brooks/Core Publishing Company

Duncan, L. G., Coastworth, J. D., \& Greenberg, M. T. (2009). A model of mindful parenting: implication for parent child relationship and prevention research. Chlinical Child and Family Psychology Review, 12(3), 255-270. doi: 10.1007/s10567-009- $\underline{0046-3}$

Dyson R., \& Renk. K. (2006) Freshmaen adaptation to university life; depressive symtoms, stress, and, copping. Journal of Clinical Psychology, 62, 1231-1244.

Finkel, E. J., \& Campbell, W. K. (2001). Selfcontrol and accommodation in close relationships: An inter-dependence analysis. Journal of Personality and Social Psychology, 81, 263-277.

Greenberg L. S. (1999). Ideal psychoterapy research; a study of significant change process. Journal of Clinical Psychology, 55, 1467-1480.

Gregoire, C. (2014). Actually TIME, This is what the 'mindful revolution' really looks like. Retrieved http://www.huffing tonpost.com/2014/02/04/this-isproof-that-mindfu n 4697734. html.

Kabat-Zinn J. (2000). Full catastrophe living: Using the wisdom of your body and mind to face stress, pain, and illness. New York: Dell Publishing.

Kabat-Zinn, J. (1998). Where you go there you are: Mindfulness meditation in everyday life. New York: Hyperion.

Kabat-Zinn, J. (2003). Mindfulness-based interventions in context: Past, present, and future. Clinical Psychology: Science and Practice, 10(2), 144-156.

Kabat-Zinn, J. (2005). Coming to our senses: Healing ourselves and the world through mindfulness. New York: Hyperion.

Kalat, J. W. (2010). Biopsikologi: Biological psychology, Buku 2. Jakarta: Salemba Humanika.

Markam, S. S., \& Markam, S. (2003). Pengantar neuro-psikologi. Jakarta: Fakultas Kedokteran Universitas Indonesia. 
Muraven, M. \& Baumeister, R. F. (2000). Self-regulation and depletion of limited resources: Does self-control resembles a muscle?. Psychological Bulletin, 126, 247-259.

Muraven, M., \& Shmueli, D. (2006). The self-control costs of fighting the temptation to drink. Psychology of Addictive Behaviors, 20, 154-160.

Muraven, M., Collins, R. L., Morsheimer, E. T., Shiffman, S., \& Paty, J. A. (2005). Daily fluctuations in self-control demands and alcohol intake. Psychology of Addictive Behaviors, 19, 140-147.

Najuddan, A. (2003). Hubungan antara kecemasan dan prestasi pada mahasiswa baru UNHAS. Karya ilmiah tidak diterbitkan. Makassar: Universitas Hasanuddin

Papalia, D. E., Olds, S. W., \& Feldman, R. D. (2007). Human development (11th ed). New York: Mc-Graw Hill.

Ritter, S. M., Karremans, S. C., \& van Schie, H. T. (2010). The role of selfregulation in derogating attractive alternatives. Journal of Experimental Social Psychology, 46, 631-637.

Schemeichel, B. J., Vohs, K. D., \& Baumeister, R. F., (2003). Intellectual performance and ego depletion; Role of the self in logical reasoning and other information processing. Journal of Personality and Social Psychology, 85, 33-46

Segal, Z. V., Williams, M. G., \& Teasdale, J. D. (2012). Mindfulness-based cognitive therapy for depression (2nd ed.). New York: Guilford Press.
Shadish, W. R., Cook, T. D., \& Campbell, D. T. (2002). Experimental and quasi experimental design for generalized causal inference. New York: Houghton Mifflin Company.

Stucke, T., \& Baumeister, R. F. (2006). Ego depletion and aggressive behavior: is the inhibition of aggression a limited resource?. European Journal of Social Psychology, 36(11), 1-13. doi: 10.1002/ejsp.285

Turner, J. S., \& Helms, D. B. (1995) Lifespan development (5th ed). Orlando: Holt, Rineheart, and Winston, Inc.

Undarwati. A., \& Prawitasari. Y. E., (2012). Pengaruh fungsi eksekutif diri dan pilihan pada ego depletion. Tesis (Tidak dipublikasikan). Universitas Gadjah Mada

Utomo, S. B. (2008). Pengaruh konseling terhadap tingkat kecemasan mahasiswa. Universitas Sebelas Maret. Surakarta.

Vohs, K. D. \& Heatherton, T. F., (2000). Self regulatory failure; a resource depletion approach. Psychological Science, 11, 249-254.

Yusainy, C. A. (2013). Overcoming aggression: Musing on mindfulness and self-control. Dissertation. Nottingham: School of Psychology, University of Nottingham.

Yusainy, C. A., \& Lawrence, C. (2014). Relating mindfulness and selfcontrol to harm to the self and to others. Personality and Individual Differences, 64, 78-83. doi: 10.1016/j.paid.2014.02.015 